\title{
Quantitative characterization of collapse and fracture pressure uncertainty based on Monte Carlo simulation
}

\author{
Sheng Ya-nan ${ }^{1} \cdot$ Li Weiting $^{1} \cdot$ Jiang Jinbao ${ }^{1} \cdot{\text { Lan } \mathrm{Kai}^{2} \cdot \mathrm{Kong} \mathrm{Hua}^{1} \cdot \text { Yan Yupeng }}^{1}$
}

Received: 16 December 2020 / Accepted: 2 April 2021 / Published online: 20 April 2021

(c) The Author(s) 2021

\begin{abstract}
The complex geological conditions of drilling, the difficulty of formation collapse and fracture pressure prediction in South Sichuan work area lead to the complex drilling and frequent failure, which seriously restricts the safe and efficient development of shale gas. In view of this problem, this paper has carried out relevant research. First of all, the existing calculation model of formation collapse and fracture pressure is established and improved; on this basis, the sources of uncertainty in the calculation model of collapse and fracture pressure are analyzed, mainly the in-situ stress and rock mechanics parameters, which have a lot of uncertainties; then, the uncertainty of rock mechanics parameters and in-situ stress is analyzed, and its probability is determined. Finally, based on Monte Carlo simulation, the quantitative characterization method of formation collapse and fracture pressure uncertainty is established. The prediction result of collapse and fracture pressure is no longer a single curve or value, but an interval, which is more practical for drilling in complex geological environment. The results of this study are helpful to better describe the collapse and fracture pressure of complex formation and can provide more valuable reference data for drilling design.
\end{abstract}

Keywords Shale gas drilling $\cdot$ Collapse and fracture pressure uncertainty $\cdot$ Monte Carlo simulation $\cdot$ Wellbore stability evaluation

\section{Introduction}

Formation collapse pressure and formation fracture pressure are the upper and lower limits of safe drilling fluid density window to maintain wellbore stability. How to accurately predict and describe formation collapse and fracture pressure are an important content to avoid wellbore instability risk (Tinggen and Zhichuan 2000; Ottesen et al. 1999). With the development of drilling to deep well complex formation and deep water, the geological environment encountered in the process of drilling is becoming more and more complex. In the actual drilling engineering, due to the particularity of the drilling engineering construction, as well as the uncertainty of geological conditions, the complexity of

Sheng Ya-nan

syn4465877@163.com

1 Drilling Engineering and Technology Research Institute, Zhongyuan Petroleum Engineering Co., Ltd, SINOPEC, Puyang 457001, China

2 Southwest Drilling Company, Zhongyuan Petroleum Engineering Co., Ltd, Chengdu 610000, China operating environment factors, the variability of construction methods and design parameters, etc., many uncertain factors will be encountered from time to time in the process of drilling construction. It is increasingly difficult to accurately predict formation collapse and fracture pressure. The rock mechanics parameters and in-situ stress input in the existing calculation model of formation collapse and fracture pressure are all treated according to the fixed value, and the prediction results of formation collapse and fracture pressure are all single value results. This method ignores the error between the prediction result and the actual result due to the uncertainty of the input parameters of the calculation model of collapse and fracture pressure (Guangfu et al. 2019; Kolawole et al. 2018; Moos and Peska 2003). The in-situ stress and rock mechanics parameters in the calculation model need to be calculated based on the indirect formula according to the seismic or logging data, and there is uncertainty (Mostafavi et al. 2011; Zhide, 2004; Limin et al. 2017). The design based on the inaccurate prediction results may lead to the risk of wellbore instability. In order to solve this problem, this paper proposes a quantitative characterization method of formation collapse and fracture 
pressure uncertainty based on Monte Carlo simulation. First of all, established and improved the existing calculation model of formation collapse and fracture pressure. On this basis, analyzed the sources of uncertainty in the calculation model of formation collapse and fracture pressure, mainly the in-situ stress and rock mechanics parameters, which are usually obtained through indirect mathematical model calculation based on seismic or logging data, so there are a lot of uncertainties. After that, the uncertainty of rock mechanical parameters and in-situ stress is analyzed, and its probability distribution is determined. Finally, based on Monte Carlo simulation, the quantitative characterization method of the uncertainty of formation collapse and fracture pressure is established. The prediction result of formation collapse and fracture pressure is not a single curve or value, but an interval range, which is more practical for drilling in complex geological environment.

\section{Methods}

\section{Quantitative calculation model of collapse and fracture pressure}

Formation collapse and fracture pressure are the upper and lower limits of safe drilling fluid density window to maintain wellbore stability (Yi et al. 2019). How to accurately predict and describe formation collapse and fracture pressure are an important content to avoid wellbore instability risk. In the calculation of formation collapse and fracture pressure, many key calculation parameters affect the results, mainly including in-situ stress and rock mechanics parameters, which can be calculated based on logging data or seismic interpretation data.

\section{(1) Rock mechanics parameters}

Rock mechanics parameters can be divided into mechanical properties and elastic properties (Xiangjun and Pingya 1999; Min et al. 2009).

a. Rock elastic properties
P-wave velocity of rock:

$V_{p}=\frac{E_{d}\left(1-\mu_{d}\right)^{0.5}}{\left[\rho_{d}\left(1+\mu_{d}\right)\left(1-2 \mu_{d}\right)\right]^{0.5}}=\frac{1}{\Delta T_{p}}$

S-wave velocity of rock:

$V_{s}=\frac{E_{d}^{0.5}}{\left[2 \rho_{b}\left(1+\mu_{d}\right)\right]^{0.5}}=\frac{1}{\Delta T_{s}}$

In formula, $\Delta T_{p}$ - Rock P-wave time difference, us $/ \mathrm{m}$. $\Delta T_{s}$-Rock S-wave time difference, us $/ \mathrm{m} . \rho_{b}$-Rock density, $\mathrm{g} / \mathrm{cm}^{3} . E_{d}$-Dynamic Young's modulus, MPa. $u_{d}$-Dynamic Poisson's ratio, dimensionless.

The transformation relationship between each rock elastic parameters:

$G=\frac{E}{2\left(1+\mu_{d}\right)} K_{b}=\frac{E}{3\left(1-2 \mu_{d}\right)} C_{b}=\frac{1}{K_{b}}$

In formula, $E$-Young's modulus, MPa. $G$-Shear modulus, MPa. $K_{b}$-Bulk modulus of elasticity, MPa. $C_{b}$-Volume compression coefficient, dimensionless.

The elastic parameters of rock can be divided into dynamic and static parameters, which can better reflect the real elastic characteristics of rock. In practical application, the dynamic elastic parameters should be converted into static elastic parameters.

(1) Dynamic elastic parameters

According to formula (1), formula (2) and formula (3), the elastic parameter formula of dynamic rock mechanics is derived, as shown in Table 1

(2) Conversion of dynamic and static elastic parameters

The transformation relationship between dynamic and static elastic parameters (Min et al. 2009):

$\mu_{s}=A_{1}+K_{1} \mu_{d} E_{s}=A_{2}+K_{2} E_{d}$
Table 1 Calculation formula of dynamic elastic parameters

\begin{tabular}{ll}
\hline Dynamic elastic parameters & Calculation formula \\
\hline Poisson's ratio $/ u_{d}$ & $\mu_{d}=\left(0.5 \Delta T_{s}^{2}-\Delta T_{p}^{2}\right) /\left(\Delta T_{s}^{2}-\Delta T_{p}^{2}\right)$ \\
Young's modulus $/ E_{d}$ & $E_{d}=\rho\left(3 \Delta T_{s}^{2}-4 \Delta T_{p}^{2}\right) /\left[\Delta T_{s}^{2}\left(\Delta T_{s}^{2}-\Delta T_{p}^{2}\right)\right.$ \\
Shear modulus $/ G$ & $G=E_{d} /\left(2\left(1+\mu_{d}\right)\right)$ \\
Bulk modulus of elasticity $/ K_{b}$ & $K_{b}=E_{d} /\left(3\left(1-2 \mu_{d}\right)\right)$ \\
Volume compression coefficient $/ C_{b}$ & $C_{b}=1 / K_{b}$ \\
Compressibility coefficient $/ C_{r}$ & $C_{r}=1 /\left(\rho_{m}\left(1 / \Delta T_{s} m^{2}-4 /\left(\Delta T_{s}^{2}-1\right)\right)\right)$ \\
Effective stress coefficient $/ \alpha$ & $\alpha=1-C_{r} / C_{b}$ \\
\hline
\end{tabular}


In formula, $\quad \mathrm{A}_{1}=\mathrm{a}_{11}+\mathrm{a}_{12} \lg \left(\sigma_{1}-\sigma_{3}\right)$

、 $\mathrm{A}_{2}=\mathrm{a}_{21}+\mathrm{a}_{22} \lg \left(\sigma_{1}-\sigma_{3}\right) 、 \mathrm{~K}_{1}=\mathrm{k}_{11}+\mathrm{k}_{12} \lg \left(\sigma_{1}-\sigma_{3}\right)$ 、

$\mathrm{K}_{2}=\mathrm{k}_{21}+\mathrm{k}_{22} \lg \left(\sigma_{1}-\sigma_{3}\right), \sigma_{1}$ and $\sigma_{3}$ are the maximum and minimum principal stresses, respectively. $a_{11} 、 a_{12}, a_{21}, a_{22}, k_{11}, k_{12}, k_{21}, k_{22}$ are regression coefficients. The above transformation relationship needs to be obtained according to the core laboratory experiments.

b. Rock mechanical properties

The calculation formula of mechanical properties is shown in Table 2.

In table, $\rho$-Rock density, $\mathrm{g} / \mathrm{cm}^{3} . V_{c}-$ Shale content, dimensionless. $\phi$-Internal friction angle, ${ }^{\circ} . M=a$ $b \times c . a 、 b$-The coefficients related to rock properties are obtained by inverse calculation of core test experiments.

(2) In-situ stress

The commonly used calculation formula of in-situ stress is (Mian et al. 2008):

$\sigma_{v}=\int G_{o} d \mathrm{H}$

$$
\left\{\begin{array}{c}
\sigma_{H}=\frac{\beta_{1} E+2 \mu\left(\sigma_{v}-\alpha G_{p}\right)}{2(1-\mu)}+\frac{\beta_{2} E}{2(1+\mu)}+\alpha G_{p} \\
\sigma_{h}=\frac{\beta_{1} E+2 \mu\left(\sigma_{v}-\alpha G_{p}\right)}{2(1-\mu)}-\frac{\beta_{2} E}{2(1+\mu)}+\alpha G_{p}
\end{array}\right.
$$

In formula, $\sigma_{v}-$ Vertical stress, MPa. $\sigma_{H}-$ Maximum horizontal in-situ stress, MPa. $\sigma_{h}$-Minimum horizontal in-situ stress, MPa. $u$-Poisson's ratio, dimensionless. E-Young's modulus, MPa. $H$-Well depth, m. $G_{p}$-Pore pressure, MPa. $\beta_{1} 、 \beta_{2}$-Coefficient of tectonic stress:

Table 2 Calculation formula of rock strength parameters

\begin{tabular}{ll}
\hline $\begin{array}{l}\text { Rock strength } \\
\text { parameters }\end{array}$ & Calculation formula \\
\hline $\begin{array}{l}\text { Uniaxial } \\
\text { compressive }\end{array}$ & $S_{C}=0.33 \rho^{2} V_{p}^{4}\left(\left(1+\mu_{d}\right) /\left(1-\mu_{d}\right)\right)^{2}\left(1-2 \mu_{d}\right)\left(1+0.78 V_{c l}\right)$ \\
strength $/ S_{c}$ & \\
Uniaxial tensile & $S_{t}=S_{c} / 12$ \\
strength $/ S_{t}$ & \\
Cohesion $/ C$ & $C=0.00544 \rho^{2} V_{p}^{4}\left(\frac{1+\mu_{d}}{1-\mu_{d}}\right)^{2}\left(1-2 \mu_{d}\right)\left(1+0.78 V_{c l}\right)$ \\
$\begin{array}{c}\text { Internal friction } \\
\text { angle } / \phi\end{array}$ & $\phi=a \ln \left[M+\left(M^{2}+1\right)^{0.5}\right]+b$ \\
\end{tabular}

$$
\left\{\begin{array}{l}
\beta_{1}=\frac{(1-\mu)\left(\sigma_{H}+\sigma_{h}\right)-2 \mu\left(\sigma_{v}-\alpha G_{p}\right)-2 \alpha(1-\mu) G_{p}}{E} \\
\beta_{2}=\frac{(1+\mu)\left(\sigma_{H}-\sigma_{h}\right)}{E}
\end{array}\right.
$$

In formula, the maximum and minimum horizontal insitu stress can be measured by various in-situ stress measurements. Other parameters are calculated according to logging data.

(3) Collapse pressure

The commonly used calculation formula of formation collapse pressure is based on the Mohr-Coulomb strength criterion (Mian et al. 2008):

$$
\begin{aligned}
\rho_{c}= & \frac{\eta\left(3 \sigma_{H}-\sigma_{h}\right)}{\left(K^{2}+\eta\right)}+\frac{\alpha \rho_{p}\left(K^{2}-1\right)}{\left(K^{2}+\eta\right)} \\
& -\frac{2 C K}{0.00981 \times H \times\left(K^{2}+\eta\right)}
\end{aligned}
$$

In formula, $\rho_{c}$-Collapse pressure, $\mathrm{g} / \mathrm{cm}^{3} . \mathrm{H}$-Well depth, m. $K=\cot \left(45^{\circ}-\phi / 2\right) . \phi$-Internal friction angle, ․ $C$-Rock cohesion, MPa. $\rho_{p}$-Pore pressure, $\mathrm{g} / \mathrm{cm}^{3}$. $\sigma_{H}$-Maximum horizontal in-situ stress, $\mathrm{g} / \mathrm{cm}^{3} . \sigma_{h}-$ Minimum horizontal in-situ stress, g/cm3. $\eta$-Nonlinear correction coefficient of stress. $\alpha$-Biot coefficient.

(4) Fracture pressure

The commonly used calculation formula of fracture pressure is (Qining 1983):

$\rho_{f}=3 \sigma_{h}-\sigma_{H}-\alpha \rho_{p}+S_{t} / 0.00981 \times H$

In formula, $\rho \mathrm{f}$-Fracture pressure, $\mathrm{g} / \mathrm{cm} 3 . S_{t}$-Uniaxial tensile strength, MPa.

\section{Analysis of uncertainty sources of collapse and fracture pressure}

According to the calculation model of formation collapse and fracture pressure, the parameters in the calculation model can be divided into three categories: well trajectory parameters, in-situ stress and rock mechanical parameters. Among them, the well trajectory can be accurately obtained according to drilling design or MWD data. The in-situ stress and rock mechanical parameters are usually calculated by indirect mathematical model based on logging or seismic interpretation data, so there are a lot of uncertainties. For the drilled well, the in-situ stress and rock mechanics parameters can be obtained by various logging data or seismic data. However, it is difficult to obtain these parameters accurately before drilling, which 
will lead to a large error or uncertainty in the pressure prediction results of the well to be drilled. Therefore, it is necessary to analyze the uncertainty of rock mechanical and in-situ stress parameters. Using the interpretation results of logging data to estimate the probability distribution of parameters, the interpretation results of formation collapse and fracture pressure with uncertainty are finally obtained.

\section{Quantitative characterization of collapse and fracture pressure uncertainty}

\section{Quantitative characterization of in-situ stress and rock mechanical parameters}

In order to analyze the uncertainty of rock mechanical parameters and in-situ stress and determine its probability distribution, it is necessary to establish the sample database of rock mechanical parameters and in-situ stress parameters. According to sequence stratigraphy (Yinye 2009): "under the same geological period and sedimentary conditions, the rocks have the same lithology, which will produce similar seismic or logging responses." Therefore, we select the logging interpretation results of rock mechanics parameters and in-situ stress within a certain depth of the same formation as samples and build the sample database. It is assumed that there are $2 n+1$ $\log$ interpretation results of rock mechanical parameters and in-situ stress in the range of well depth $\Delta H$. They are treated as a set of measurement samples, as shown in Fig. 1.

$\Delta H$ is the sample interval, and its value is twice the range of theoretical variogram model in the sample formation group. Then, the probability distributions of rock mechanical parameters and in-situ stress are calculated by using normal information diffusion estimation theory (Yifeng et al. 2016; Shushen 2001). The probability density functions of rock mechanical parameters and in-situ stress $X$ are assumed to be $f(x)$. Finally, the normal information diffusion of $f(x)$ is estimated as follows:

$\tilde{f}_{i}(x)=\frac{1}{\sqrt{2 \pi}(2 n+1) h} \sum_{j=i-n}^{i+n}\left\{\exp \left[-\frac{\left(x-x_{j}\right)^{2}}{2 h^{2}}\right]\right\}$

In formula, $h-$ Diffusion coefficient, $\mathrm{m}$.

$h=\frac{\lambda\left(x_{\max }-x_{\min }\right)}{2 n}$

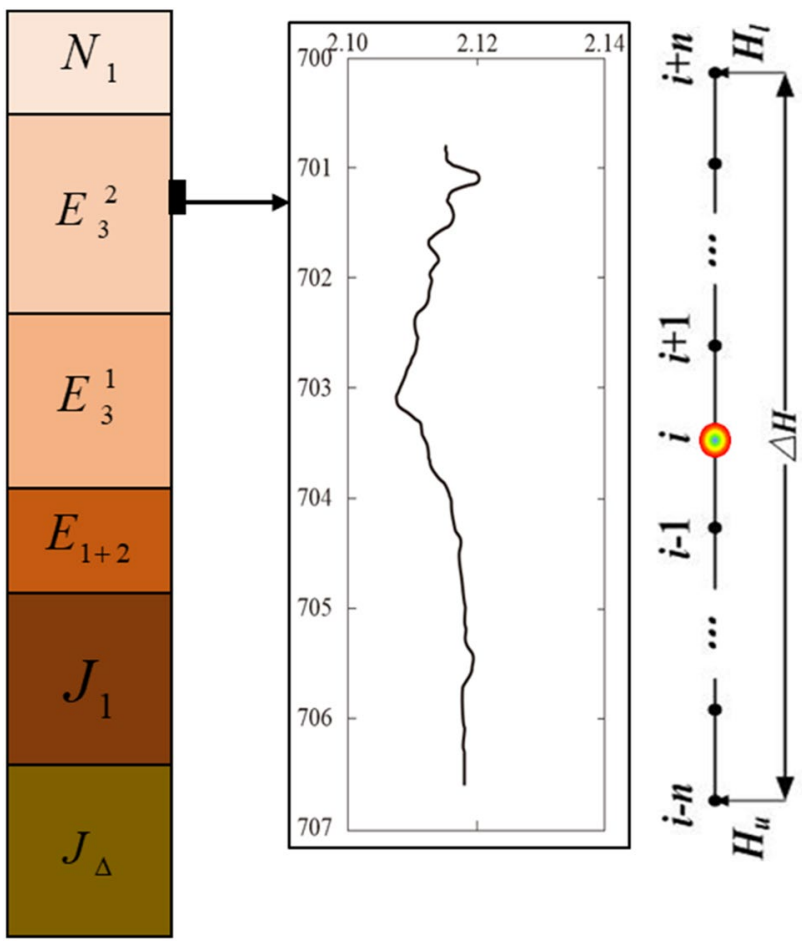

Fig. 1 Diagram of rock mechanics parameters and in-situ stress analysis sample

Table 3 Corresponding relation between $\lambda$ and sample number $(2 n+1)$

\begin{tabular}{llllll}
\hline $2 n+1$ & $\lambda$ & $2 n+1$ & $\lambda$ & $(2 n+1)$ & $\lambda$ \\
\hline 3 & 0.84932180 & 8 & 1.395189816 & 13 & 1.420698795 \\
4 & 1.273982782 & 9 & 1.422962345 & 14 & 1.420669671 \\
5 & 1.698643675 & 10 & 1.416278786 & 15 & 1.420693321 \\
6 & 1.336252561 & 11 & 1.420835443 & 16 & 1.420692226 \\
7 & 1.445461208 & 12 & 1.420269570 & 17 & 1.420693101 \\
\hline
\end{tabular}

In formula, $x_{\max } 、 x_{\min }$-The maximum and minimum value of rock mechanical parameters and in-situ stress $X$ in the target formation. The coefficient $\lambda$ can be obtained according to Table 3:

\section{Quantitative characterization of collapse and fracture pressure uncertainty}

The steps to quantify the uncertainty of collapse and fracture pressure based on Monte Carlo simulation (Sundar and Witt 1995; Junhu 2007) are as follows:

(1) Determination of the rock mechanical parameters and in-situ stress probability distributions. According to the 
above method, the analysis sample database of model input parameters at any depth $h$ position is constructed: $F_{N} \sim f\left(x_{1}\right), f\left(x_{2}\right), \cdots, f\left(x_{n}\right)$

(2) Construction of random simulation sample sets. The random values are generated according to the probability distribution of the rock mechanical parameters and in-situ stress. The collapse and fracture pressure at any depth can be obtained by substituting them into the calculation models.

(3) Construction of collapse and fracture pressure sample sets. The probability distribution and cumulative probability distribution function of formation collapse and fracture pressure at any depth are obtained by selecting normal distribution form to fit the statistical analysis calculation results: $f_{h}\left(P_{t, f}\right) 、 F_{h}\left(P_{t, f}\right)$.

(4) Quantitative characterization of collapse and fracture pressure uncertainty. Through the above methods, the cumulative probability of collapse and fracture pressure at different depths can be obtained, which can form the set:

$$
\begin{aligned}
F\left(P_{t, f}\right)=\{ & \left\{F_{h_{1}}\left(P_{t, f}\right), F_{h_{2}}\left(P_{t, f}\right), F_{h_{3}}\left(P_{t, f}\right),\right. \\
& \left.\ldots, F_{h_{i}}\left(P_{t, f}\right), \ldots, F_{h_{n}}\left(P_{t, f}\right)\right\}
\end{aligned}
$$

In formula, $\left(P_{t, f}\right)_{h_{i} j}$-The collapse and fracture pressure with cumulative probability $j$ at the depth of $h_{i}$. Take the same cumulative probability value $j_{0}$ to form the new set:

$$
\begin{aligned}
\left(P_{t, f}\right)_{j_{0}}= & \left\{\left(P_{t, f}\right)_{h_{0} j_{0}},\left(P_{t, f}\right)_{h_{1}, j_{0}},\left(P_{t, f}\right)_{h_{2}, j_{0}},\right. \\
& \left.\ldots,\left(P_{t, f}\right)_{h_{i} j_{0}}, \ldots,\left(P_{t, f}\right)_{h_{n}, j_{0}}\right\}
\end{aligned}
$$

In formula, $\left(P_{t, f}\right)_{j_{1}}\left(P_{t, f}\right)_{j_{2}}$-The collapse and fracture pressure with cumulative probability $j_{1} 、 j_{2}\left(j_{1}<j_{2}\right)$. The two curves constitute the interval of collapse and fracture pressure with a confidence of $\left|j_{1}-j_{2}\right| \times 100 \%$, which indicates that the probability that the actual collapse and fracture pressure in $\left[\left(P_{t, f}\right)_{h_{i} j_{1}},\left(P_{t, f}\right)_{h_{i} j_{2}}\right]$ is $\left|j_{1}-j_{2}\right| \times 100 \%$.

\section{Results and discussions}

Well XX is a deep shale gas exploration well in South Sichuan work area, taking XX as an example for analysis. Firstly, the probability distributions of rock mechanical parameters and in-situ stress at any depth are calculated. Table 4 shows the calculation results of parameter probability at the depth of $2000 \mathrm{~m}$. Then, the probability distributions of collapse and fracture pressure at this depth are obtained, as shown in Fig. 2 and Fig. 3. Finally, the interval profile of collapse and fracture pressure with $90 \%$ confidence is obtained by programming calculation, as shown in Fig. 4.

The conclusion is as follows: the prediction result of collapse and fracture pressure is no longer a single curve or value, but an interval, which is more practical for drilling in complex geological environment. The results of this study are helpful to better describe the collapse and fracture pressure of complex formation and can provide more valuable reference data for drilling design.

\section{Conclusions and recommendations}

a. In the existing calculation model of collapse and fracture pressure, the input rock mechanical parameters and insitu stress are all treated according to the fixed value, and the obtained pressure prediction results are all single value results. This method ignores the error between the predicted result and the actual result due to the uncertainty of the input calculation parameters.

b. In this paper, the existing calculation model of formation collapse and fracture pressure is established and improved, and the Monte-Carlo simulation method is used to characterize the collapse and fracture pressure, and the uncertainty quantitative description method of formation collapse and fracture pressure is established.
Table 4 Probability distribution characteristic parameters of each parameter

\begin{tabular}{llll}
\hline Parameters & Unit & Distribution form & characteristic parameter \\
\hline Vertical stress- $\sigma_{v}$ & $\mathrm{~g} / \mathrm{cm}^{3}$ & Normal distribution $N\left(u, \sigma^{2}\right)$ & $u=2.396, \sigma=0.013$ \\
Maximum horizontal in-situ stress $-\sigma_{H}$ & $\mathrm{~g} / \mathrm{cm}^{3}$ & & $u=2.25, \sigma=0.042$ \\
Minimum horizontal in-situ stress- $\sigma_{h}$ & $\mathrm{~g} / \mathrm{cm}^{3}$ & $u=2.07, \sigma=0.058$ \\
Uniaxial tensile strength—S & $\mathrm{MPa}$ & $u=1.72, \sigma=0.157$ \\
Pore pressure- $\rho_{p}$ & $\mathrm{~g} / \mathrm{cm}^{3}$ & $u=1.08, \sigma=0.093$ \\
Internal friction angle- $\phi$ & $\circ$ & $u=32.3, \sigma=1.78$ \\
Rock cohesion-C & $\mathrm{MPa}$ & $u=3.4, \sigma=0.17$ \\
\hline
\end{tabular}


Fig. 2 Probability distribution of collapse pressure at depth $2000 \mathrm{~m}$
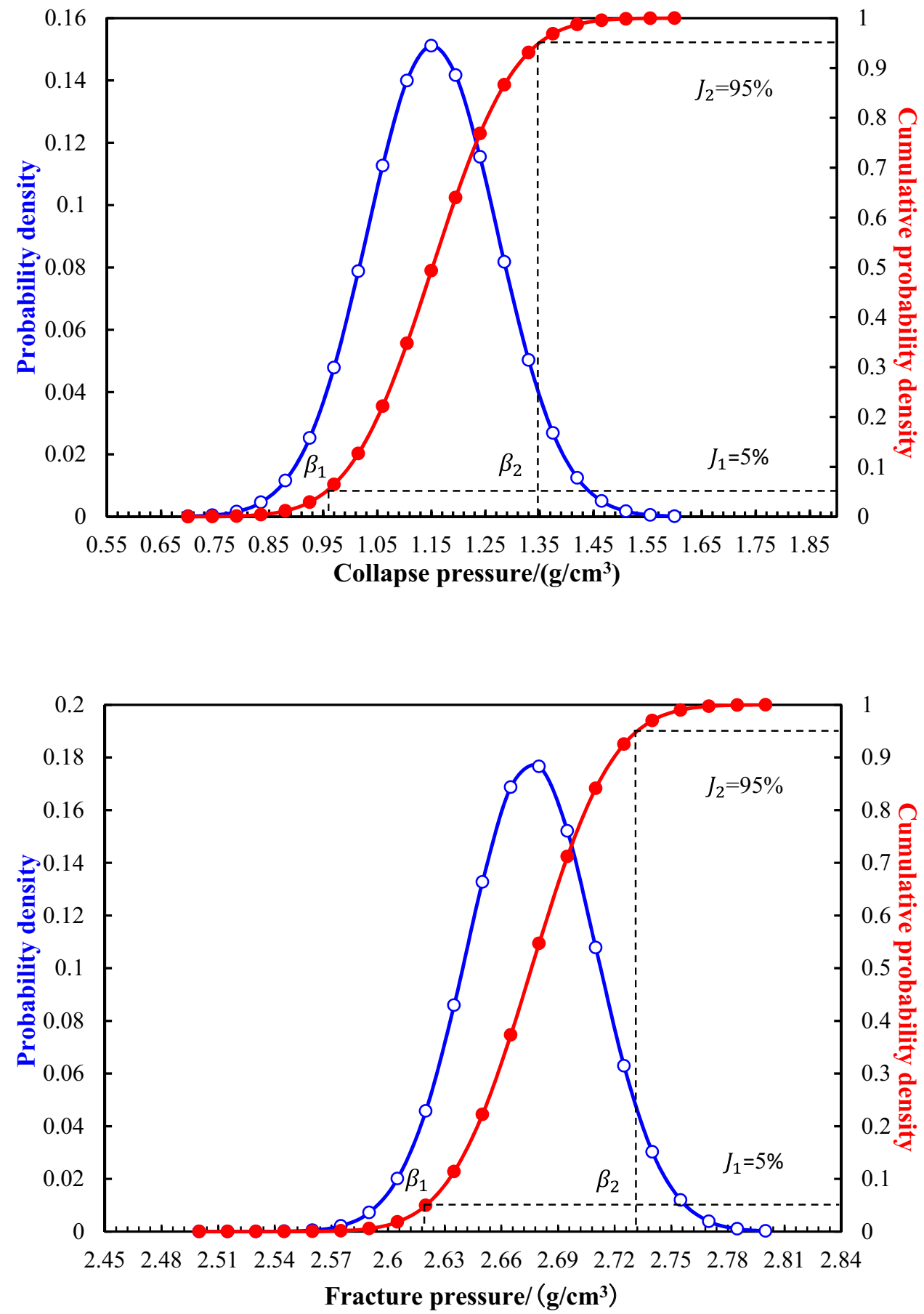

Fig. 3 Probability distribution of fracture pressure at depth $2000 \mathrm{~m}$

Fracture pressure/ $\left(\mathbf{g} / \mathrm{cm}^{3}\right)$ c. According to the method established in this paper, the predicted collapse and fracture pressure are no longer a single fixed value curve, but a pressure interval with probability information, which is more practical for drilling in complex geological environment. The results of this study are helpful to better describe the collapse and fracture pressure of complex formation and can provide more valuable reference data for drilling design. 
Fig. 4 Collapse and fracture pressure interval with confidence level $90 \%$ of XX
Collapse pressure/ $\left(\mathrm{g} / \mathrm{cm}^{3}\right)$

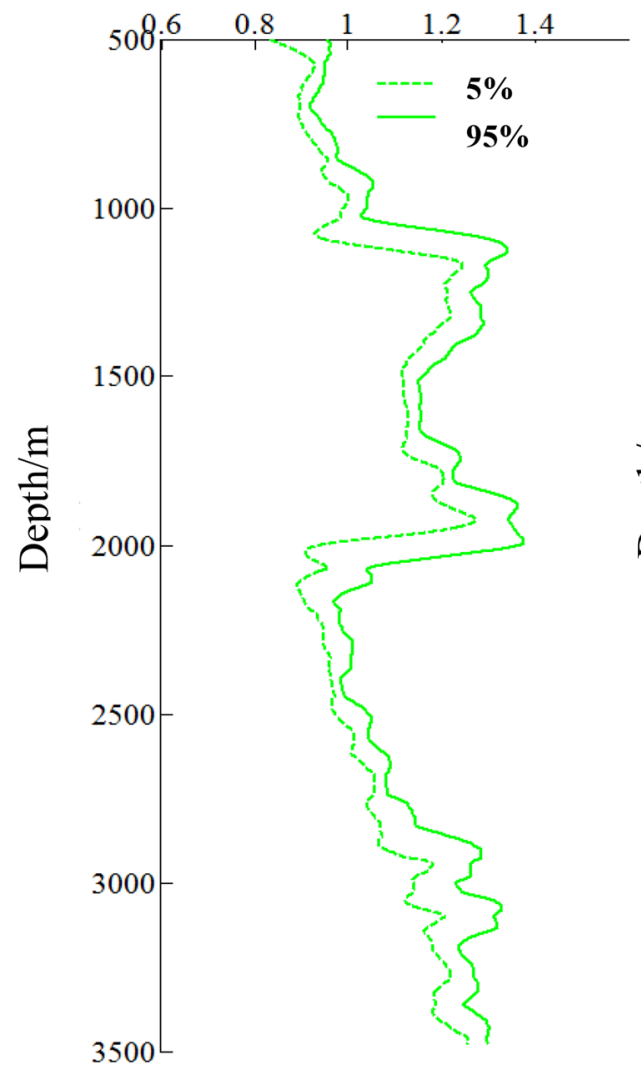

Fracture pressure/ $\left(\mathrm{g} / \mathrm{cm}^{3}\right)$

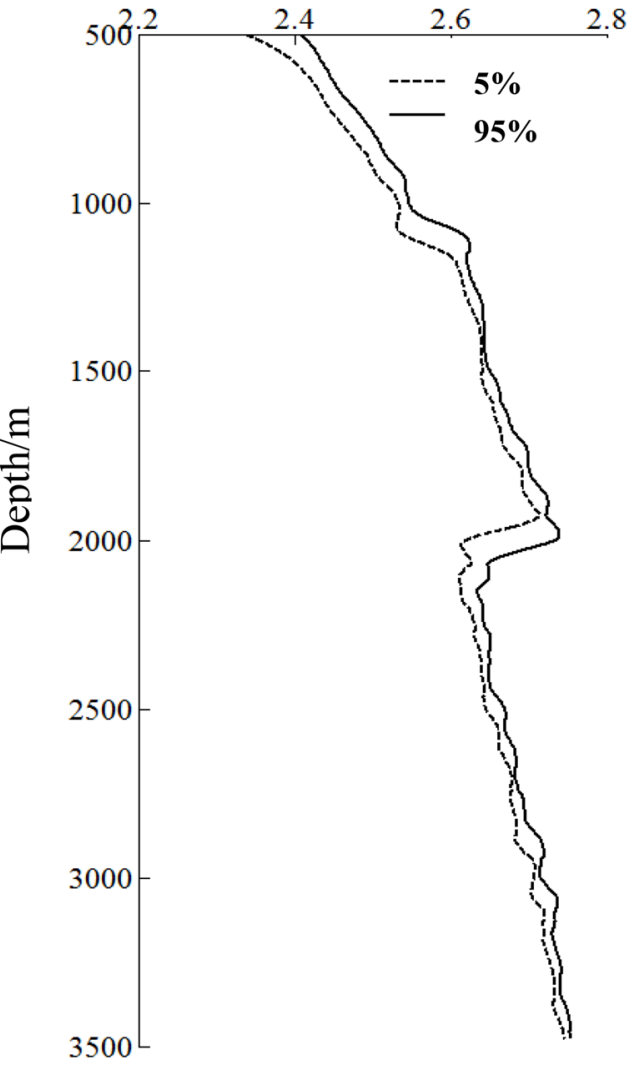

Acknowledgement The genuine MATLAB software is used in this paper.

Funding The authors received no specific funding for this work.

Open Access This article is licensed under a Creative Commons Attribution 4.0 International License, which permits use, sharing, adaptation, distribution and reproduction in any medium or format, as long as you give appropriate credit to the original author(s) and the source, provide a link to the Creative Commons licence, and indicate if changes were made. The images or other third party material in this article are included in the article's Creative Commons licence, unless indicated otherwise in a credit line to the material. If material is not included in the article's Creative Commons licence and your intended use is not permitted by statutory regulation or exceeds the permitted use, you will need to obtain permission directly from the copyright holder. To view a copy of this licence, visit http://creativecommons.org/licenses/by/4.0/.

\section{References}

Guangfu Z, Ming T, Shiming H (2019) Prediction of collapse pressure and optimization of borehole trajectory in coal measures [J]. Oil Drill Product Technol 41(4):405-411

Junhu W (2007) Application of Monte Carlo method in system engineering $[\mathrm{M}]$. Xi' an Jiaotong University Press, Xi'an

Kolawole O, Federer G, Szabo I 2018 Formation Susceptibility to Wellbore Instability and Sand Production in the Pannonian
Basin, Hungary[C]// 52nd U.S. Rock Mechanics/ Geomechanics Symposium, 17-20

Limin L, Yanan S, Xiaopo L et al (2017) Prediction method of formation fracture pressure with credibility before drilling [J]. Fault Block Oil Gas Field 24(1):112-115

Mian C, Yan J, Guangqing Z (2008) Mechanics of Petroleum Engineering $[\mathrm{M}]$. Science Press, Beijing

Min L, Zhanghua L, Shichun C et al (2009) Study on rock mechanics parameter test and formation fracture pressure prediction[J]. Oil Srill Product Technol 31(5):15-18

Moos D, Peska P (2003) Comprehensive wellbore stability analysis utilizing quantitative risk assessment [J]. J Petrol Sci Eng 38(3):97-109

Mostafavi S, Adnoy B, Hareland G (2011) Model based uncertainty assessment of wellbore stability analyses and downhole pressure estimations[J]. J Am Rock Mech 12(5):60-65

Ottesen S. W., Zheng R. H., Mccann R. C. Borehole stability assessment using quantitative risk analysis[C]. SPE 52864, 1999.

Qining F (1983) Formula and method of calculating formation fracture pressure with logging data[J]. J China Univ Pet (Nat Sci Ed) 11(3):41-48

Shushen L (2001) Statistical processing and error analysis of test data [J]. Phys Chem Inspect: Phys 37(2):88-91

Sundar A, Witt F (1995) Probabilistic structural mechanics handbook [M]. Springer, Berlin

Tinggen C, Zhichuan G (2000) Theory and technology of drilling engineering $[\mathrm{M}]$. Petroleum University Press, Dongying, pp 51-54

Xiangjun L, Pingya L (1999) The application and development of well logging in the study of wellbore stability[J]. Nat Gas Ind 19(6):33-35 
Yifeng H, Xibin LI, Huanzhen Z (2016) Inference of probability distribution of large sample geotechnical parameters based on normal information diffusion principle [J]. Res Develop Sci Technol 38(2):249-253

Yinye W (2009) Principles of sequence stratigraphy [M]. Petroleum Industry Press, Beijing

Yi W, Renjun X, Shujie L et al (2019) The stability law of high temperature and high pressure vertical well wall considering temperature effect[J]. Fault Block Oil Gas Field 26(2):253-256
Zhide L 2004 Study on the evaluation method of wellbore stability logging in carbonate formation [D]. Southwest Petroleum Institute

Publisher's Note Springer Nature remains neutral with regard to jurisdictional claims in published maps and institutional affiliations. 